\title{
Sociologia da saúde na França
}

\section{The sociology of health in France}

\author{
Miguel Ângelo Montagner \\ Faculdade de Ciências Médicas/Unicamp \\ Rua Angela Tafner, 55 C1/32 \\ 13050-191 Campinas — SP Brasil \\ montagner@fcm.unicamp.br \\ Everardo Duarte Nunes \\ Professor da Faculdade de Ciências Médicas/Unicamp \\ Rua Itala Gomes Vaz Carvalho, 60 \\ 13066-301 Campinas — SP Brasil \\ evernunes@uol.com.br
}

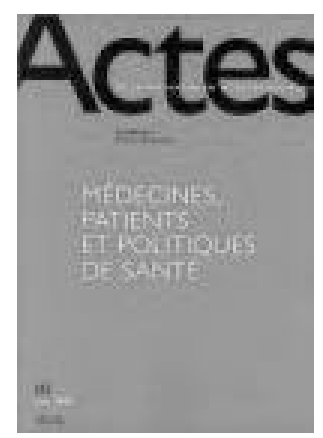

Actes de la Recherche en Sciences Sociales Médecines, patients et politiques de santé, no 143 , junho de 2002
C om esta resenha damos continuidade aos estudos realizados anteriormente sobre as publicações no campo da sociologia da saúde na França, desenvolvidas por Nunes (2003), com uma visão geral desse campo, e Montagner (2003), referente aos artigos publicados nas Actes de la Recherche en Sciences Sociales, período de 1975 a 2001. Neste segundo trabalho, procuramos compreender o tema saúde dentro do universo teórico de Pierre Bourdieu. A idéia central, sob a perspectiva do próprio filósofo, era a de que, ao utilizar o material das Actes como base documental, poder-se-ia entender que a acumulação de capital simbólico realiza-se, no âmbito da comunidade acadêmica, cada vez mais em torno da produção e publicação de artigos. Nesse caso, constata-se que a estratégia de fundação da revista Actes de la Recherche en Sciences Sociales ocorreu no momento de busca de autonomia, por parte do campo intelectual, de uma 'escola de pensamento', quando os veículos de legitimação não eram mais suficientes para divulgar as obras e os trabalhos em curso. Ou melhor, era chegada a hora da consagração de uma vanguarda, o grupo de intelectuais que se formava ao redor da perspectiva elaborada por Bourdieu.

Actes de la Recherche en Sciences Sociales foi uma das últimas revistas lançadas na França, em 1975, e seguiu um movimento de criação de novos veículos iniciado nos anos 1960 (Chenu, 2002). Com a publicação do número 143, em junho de 2002, intitulado 'Médecines, patients et politiques de santé, a revista voltava a conceder espaço especial à saúde, fato que ocorrera uma única vez, em 1987, com o número 68, dedicado a Épidémies, malades, médecins. Sendo um acontecimento incomum, não poderíamos deixar de notar e relacionar esse novo número com a história da revista Actes e a sociologia médica.

Embora essas publicações especiais sejam de pouca expressão numérica, a produção ligada ao tema da medicina tem uma representação importante. Louis Pinto (1996) apontou que a sociologia dos intelectuais chega a atingir 10\% da produção da Actes no período de 1975 a 1985, campo importante na obra de Pierre Bourdieu e de seu grupo. Constatamos que a temática da saúde atinge $4,9 \%$ da produção no mesmo período, o que indica uma 
representatividade expressiva para o tema, índice que se mantém no período que vai de 1975 a 2001 - em torno de 4,8\%.

A edição especial 'Médecines, patients et politiques de santé' é composta de dez artigos que guardam e refletem as características das publicações em torno da saúde ao longo da história da revista. Os autores dos artigos são predominantemente franceses, ligados ao referencial metodológico do grupo de Bourdieu, mas a revista concede uma abertura a autores conhecidos e destacados da comunidade científica internacional. A estratégia de criar uma teia transnacional de pesquisadores foi perseguida, como apontou Miceli (27.1.2002), desde a fundação da Actes. Um exemplo dela foi a criação do encarte Líber, ligado a Actes, tratando de inúmeros temas afetos à comunidade científica internacional. Da mesma forma, a sociologia da saúde possui, no períodico, esse caráter internacionalizado; e mais, esta característica apresenta-se acentuada: nos dois números especiais dedicados a este tema, a quantidade de autores não franceses é grande. Além disso, do total de artigos relacionados à sociologia médica, é grande a representatividade de trabalhos traduzidos para o francês.

Além da característica internacional, os artigos da Actes referentes à saúde guardam outras peculiaridades. Uma, a de abrangerem diversos campos de estudo e tomarem como objeto aspectos não clássicos do mundo social ou pouco estudados, como aliás sempre aconteceu com os artigos e autores da própria revista. Esta tradição será encontrada nos artigos que abordam a temática médica e de saúde, o que dificulta sua classificação dentro dos padrões mais convencionais da sociologia médica. Este é o caso do artigo de Aaron Vitalis Cicourel, que inaugura o número 143, 'La gestion des rendezvous dans un service médical spécialisé. Organisation et communication en régime de "surcharge cognitive"". Cicourel nasceu em 1928, foi aluno de Alfred Schütz e iniciou com Harold Garfinkel a corrente sociológica da etnometodogia. De um modo geral, esta perspectiva centra-se na busca da compreensão do conhecimento produzido pelo senso comum e pelo raciocínio empírico em situações sociais específicas. Isso significa compreender o contexto social, ou melhor, o contexto microssocial em que a ação acontece e se enraíza. Cicourel vai além e propõe uma sociologia cognitiva, em uma abordagem que busca integrar três aspectos fundamentais: a linguagem, a significação das ações e o conhecimento gerado. Tal integração pressupõe um amálgama entre os aspectos contextuais (micro) e os aspectos objetivos ligados à sociedade como um todo (macro), de forma a explicar como as práticas sociais são mantidas estáveis e organizam o mundo social. É este o pressuposto com que o autor abre seu artigo, chamando a atenção para a 'complexidade informacional' das organizações de trabalho em suas atividades cotidianas, que possibilitam obter informações e compreender melhor os problemas ditos estruturais, pois as práticas, sobretudo as discursivas, podem iluminar de dentro para fora a ordem social. No artigo, ele trata das práticas organizacionais e discursivas presentes nas rotinas dos atendimentos, mas negligenciadas na prestação de serviços de saúde. A saber: os problemas da organização do tempo em um serviço médico especializado, especialmente quando os pacientes deixam de atender à consulta agendada, ou quando um paciente deve ser 'intercalado' em uma agenda sobrecarregada de consultas. 
O agente a ser estudado foi uma atendente-secretária, em um posto público de prestação de assistência médica, organização burocrática presidida cotidianamente por 'práticas organizacionais' baseadas em uma linguagem chamada por Cicourel de "conversação institucional". Para o autor, os aspectos diários desses comportamentos burocráticos não foram suficientemente estudados, bem como suas trocas discursivas. Os problemas estariam ligados, segundo o autor, à "sobrecarga cognitiva", em virtude das tensas experiências pessoais e interpessoais nos lugares de trabalho, onde a colaboração é difícil e as necessidades das organizações pesam sobre os indivíduos. A idéia central é mostrar os dilemas teóricos e metodológicos a serem enfrentados por um pesquisador contemporâneo, ao lidar com as práticas sociais, a linguagem dos agentes sociais e sua própria prática discursiva - inserida, ela também, em um processo histórico e social mais amplo.

Analisando o material gravado dessas práticas discursivas da organização médica, além da observação participante no local de trabalho da funcionária, o autor esforça-se para apontar as restrições organizacionais, as relações de poder, as obrigações e as demandas sobre os indivíduos. Ele nos convence que é fundamental focarmos nosso olhar nos aspectos microssociais e seus em seus contextos, se quisermos entender em profundidade as estruturas das organizações e seus processos discursivos.

Outro autor preocupado sobretudo com as relações entre o macro e o microssocial, em especial aquelas ligadas à história ocidental européia, é Jürgen Schlumbohm, autor do artigo 'Comment l'obstétrique est devenue une science. La maternité de l'université de Gottingen, 1751-1830'. Este historiador social especializou-se em microestudos de comunidades préindustriais e seus padrões demográficos, relacionando os padrões locais às variáveis globais de mudanças demográficas. Em suma, busca relacionar micro-história e macromodelos de análise ligados a padrões familiares, sociais e individuais postulados pela história tradicional e pela história da cultura.

Schlumbohm não trabalha sob o ponto de vista de que há 'duas culturas', a científica e a literária, mas propõe a existência de somente uma - a história cultural de um povo, incluindo e imiscuindo nesse escopo todo tipo de conhecimento. Portanto, a ciência é entendida como uma construção social, parte integrante da cultura. Com esta linha de abordagem, o artigo explora, baseado em documentos, o modo como o hospital-maternidade da Universidade de Göttingen atingiu seus três objetivos: formar estudantes de medicina, formar parteiras e fornecer um abrigo às parturientes necessitadas. Ao mesmo tempo, tais objetivos sofreram as injunções históricas e dos poderes políticos. Analisa o papel do hospital e de seus pacientes na emergência de uma obstetrícia científica marcada pela presença masculina.

Tomar os temas médicos como objeto utilizando o método histórico é a prática de outro articulista da Actes, Olivier Faure, em seu texto 'L'boméopathie entre contestation et intégration'. Faure, professor de história contemporânea da Universidade de Lyon 3, realiza pesquisas no Centro Pierre Leon de História Econômica e Social, tendo como temas: história social da medicina, medicalização, história dos hospitais e da farmácia, homeopatia, mutualismo e as formas de regulação dos sistemas de saúde. 
Em seu artigo, pesquisa os determinantes sociais do sucesso da homeopatia, mais que suas consistências internas como ciência, explorando as relações entre essa doutrina e o positivismo francês, as correntes espíritas e espiritualistas e também a maçonaria. Além de uma teia de relações contraditórias, permanece na visão do autor, a grande capacidade adaptativa dos homeopatas às tendências sociais. Faure contesta a crença comum que justifica a homeopatia como um método que repousa sobre a eficácia das leis de similitude. Ao contrário; o autor defende que seu sucesso deve-se à capacidade de responder às aspirações da sociedade: entre 1910-1930, ela se torna uma indústria capitalista de medicamentos e aproveita-se do viés contestatório de uma medicina paralela. Exemplifica com a homeopatia o fato de que, muitas vezes, uma doutrina médica é elaborada mais em torno de práticas ideológicas e financeiras do que puramente científicas.

Outra autora, de forma parecida e com igual sagacidade, Marie Jaisson, socióloga da Universidade François Rabelais, analisa a profissão médica. Em 'L'honneurperdu du généraliste', traça uma genealogia, em sentido quase literal, do atual médico generalista e também dos médicos especialistas. Descortinando uma história de 'longa duração', a autora compara a prática dos médicos generalistas atuais com o modo de atuação dos 'oficiais de saúde' do século XIX. Se, naquele século, por meio da lei pósrevolucionária de 1803, a carreira médica dividira-se em duas uma pela obtenção de um doutorado e outra, de um brevê de oficial da saúde - o mesmo acontece no século XX, a partir dos anos 1950, com a seleção dos recém-formados ou para o internato em um hospital visando à especialização, ou um curso de menor duração, que leva a uma formação de médico generalista.

A polarização observada no século XIX entre dominantes e dominados, doutores em medicina e oficiais de saúde conserva-se sob outras formas, mas com igual força. A estrutura social mantém sua força e recoloca no espaço das práticas médicas a mesma polarização, sob a máscara de oposição entre médicos especialistas ligados aos centros urbanos e médicos generalistas ligados ao campo.

Ainda nessa linha, seu segundo trabalho, 'La mort aurait-elle mauvais genre? La structure des spécialités médicales à l'épreuve de la morphologie sociale', busca analisar como as lutas sociais conduzem a modificações internas na estrutura dos serviços médicos. Em suma, Jaisson realiza uma 'objetivação morfológica', analisando o conjunto das especialidades médicas em sua totalidade, objetivação entendida no sentido particular pelo qual a autora toma o conceito de 'estrutura', utilizando-se das concepções de estrutura social de Bourdieu e Halbwachs. Ela lança mão de uma grande massa de dados sobre o ensino superior na França, com o fito de traçar as mudanças ocorridas na morfologia do espaço médico, constatando que houve um processo de feminilização que se manifesta diferencialmente de acordo com a especialidade médica e origem social dos estudantes. Este processo tende a polarizar-se a partir dos anos 1990, criando grupos diferenciados de especialistas.

Jaisson desenha, baseada em seus dados estatísticos, uma lógica estrutural dupla que acaba por se traduzir em uma morfologia específica: as especialidades em que há uma forte taxa cotidiana de mortalidade 
são evitadas pelas mulheres e pelos estudantes oriundos das classes dominantes da sociedade. Em tais especialidades, concentram-se homens de baixo estrato social. Ou seja, a estrutura social das especialidades médicas consolidou-se em uma polarização da divisão por sexo e origem social dos especialistas, consolidação esta que teve por objetivo "colocar a morte, potencial ou certa, de seus futuros pacientes, à distância”.

Ainda na linha da história social, a professora adjunta do Departamento de História da Universidade de Montreal, pesquisadora ligada ao Cetase - Centro de Estudos da Ásia do Leste - Laurence Monnais-Rousselot, publica seu artigo Paradoxes d'une médicalisation coloniale. La professionnalisation du "médecin indochinois" au XXe siècle. O estudo busca traçar a história da profissionalização de um novo médico nativo, ensinado e treinado nos moldes da moderna medicina ocidental. Imbuída da missão civilizadora da metrópole, a escola de medicina de Hanói seria a primeira a formar uma elite médica na colônia a se contrapor à então existente, heterogênea e não estruturada claramente.

No artigo, a autora esforça-se por revelar as realidades inerentes ao contexto de colonização e manutenção da relação dominante/dominado também no campo médico, da mesma maneira que no campo político e econômico. Esses novos médicos, legítimos para sociedade local mas 'médicos auxiliares' para sistema colonial, só seriam emancipados e obteriam autonomia sobre o exercício de sua profissão com a retirada da França da Indochina e a proclamação da independência do Vietnã. Assim, o objetivo é evidenciar a defesa e a prática de uma medicina nacional que seja a síntese de duas tradições, a importada e a nativa. Elaborar com profundidade as condições da prática e as próprias características da medicina no Vietnã, buscando conciliar a herança da formação européia e revalorizar a medicina e as práticas tradicionais milenares, é uma tarefa iniciada pela autora.

Além desses estudos preocupados em entender o desenrolar histórico da medicina, observam-se duas outras grandes linhas de análise dentre os artigos desse número da Actes. Uma relacionada aos aspectos econômicos e outra, aos aspectos cognitivos e psicológicos da experiência da saúde e da doença, analisando a complexidade da relação entre o doente e aqueles que dele cuidam. Além do artigo de Aaron Cicourel, mencionado e alinhado com a corrente etnometodológica norte-americana, os artigos de Goffman e Kleinman perseguem esses objetivos.

Dentro da primeira linha de pesquisas inclúi-se Une réforme symbolique de la sécurité sociale. Les médias et "le trou de la Sécu", de Julien Duval. O autor, diretor de pesquisas do Centre National de Recherche Scientifique (CNRS) e estudioso da mídia francesa, centra suas considerações em um problema multissetorial que se tornou um mito: o déficit da seguridade francesa. Ao mesmo tempo político, burocrático e econômico, além de midiático, este mito tem origem em um problema de contabilidade, distante dos objetivos específicos de uma política social. Uma possível explicação parece ser o papel da mídia na construção de problemas políticos, além da contribuição dos agentes econômicos aliados ao Estado na hostilidade à seguridade social. O autor procura desmontar essa 'mitologia coletiva ativa', 
mostrando o papel da mídia e do ambiente político nas discussões repetitivas sobre o tema.

$\mathrm{Na}$ esteira da temática econômica, Marina Serré faz uma análise sociológica aprofundada sobre a gênese de um novo campo de estudos ligado à saúde, no artigo 'De l'économie médicale à l'économie de la santé. Genèse d'une discipline scientifique et transformations de l'action publiqué. Ela mostra que as políticas de saúde sofreram, nas duas últimas décadas, profundas transformações, analisadas por meio das relações entre ação pública e produção científica. A passagem da economia médica, dominada precipuamente por médicos, à economia da saúde, majoritariamente controlada pelos economistas e inserida no campo econômico, representa a autonomização de uma disciplina científica e a sua internacionalização em torno de um modelo neoclássico de inspiração norte-americana. Este processo é particularizado pela autora com a análise das lógicas próprias do campo científico da economia da saúde, de sua gênese, de suas formas de cooptação e dos debates e controvérsias que o animam.

Além desses estudos, a revista apresenta três instigantes abordagens da medicina e da saúde, coincidentemente de autores norte-americanos que fogem ao estrutural-funcionalismo parsoniano.

Apesar de já fartamente citado na área de estudos sociomédicos, Erving Goffman (1922-1982) continua a ser um autor obrigatório, com uma obra que possui muitos desdobramentos que vão além do célebre livro Asylums. É justamente essa dimensão que Yves Winkin, tradutor do artigo, busca fornecer para o público francês, apresentando 'Role distance', um dos dois ensaios que compõem Encounters: two studies in the sociology of interaction, livro de 1961. O título do ensaio adotado em francês foi ' $L a$ "distance au rôle" en salle d'opération'. O interesse imediato do artigo do Winking é mostrar a maneira arguta com que Goffman apreende uma das noções-chave do funcionalismo, o de papel social. Utilizando-se de um conceito caro à sua teoria, o de desvio, Goffman propõe a idéia de que os indivíduos sempre conservam uma margem relevante de manobra e jamais aderem completamente ao seu papel social. Dessa maneira, tendem a estabelecer uma 'distância do papel', cuja atuação acontece em todos os lugares da vida social e exerce sua força nas interações sociais.

No caso desse ensaio, o ambiente de estudo escolhido por Goffman foi a sala de cirurgia e o objeto de estudo, as interações que ali ocorreram. Mesmo nesta situação de extrema delimitação de papéis e formalidade, advinda de um longo treinamento profissional, aparecem os indicadores da distância do papel e surgem os desvios que levam à uma performance diferenciada de cada indivíduo, não estipulada no papel social. Tal diferenciação dependerá do grau de familiaridade e de, para usar um termo de Bourdieu, legitimidade do indivíduo em seu papel. A extrema familiaridade permite o distanciamento e a pouca legitimidade leva à adesão irrestrita a uma conformidade padronizada. Esta escala, proposta por Goffman, mostra que os papéis sociais são flexíveis e, como conceitos, inadequados para entendermos as ações em sociedade de maneira completa, sendo preciso lançar mão de outros termos.

Nesse sentido situa-se o artigo que encerra esse número da revista, de Arthur Kleinman, 'Santé et stigmate. Note sur le danger, l'expérience morale 
et les sciences sociales de la santê. Kleinman, reconhecido antropólogo médico, trabalha em uma seara muito próxima de Goffman, preocupado com as relações sociais dos indivíduos em situação real e cotidiana. Recorre a conceitos daquele autor, como estigma e teoria do rótulo, mas com diferenças. Para tanto, realiza nesse estudo uma pequena crítica à maneira quase consensual com que os pesquisadores voltados para essa área olham a questão: o rótulo ou estigma advém de algum handicap pessoal e gera conseqüências sociais visíveis. O autor propõe uma visão instigante: nosso mundo social, nossas sociedades, nossas comunidades geram as necessidades de rotulação e de estigmatização; e mais, decidem e escolhem indivíduos que deverão ser rotulados. As necessidades de estigmatização são resultantes das nossas sensações cotidianas de perigo, ou melhor, de nosso senso prático — no sentido de Bourdieu — de perigos reais nas situações do dia-a-dia. Modificar essa realidade humana em cada local exigiria abordagens de dentro dessas situações, considerando as experiências ordinárias que ocorrem nos processos de rotulação. Segundo o autor, a ajuda que as ciências sociais poderiam oferecer nesse processo seriam estudos mais aprofundados sobre os fundamentos sociais da saúde e do bem-estar, produzindo e disseminando uma nova ciência social.

A riqueza e profundidade dos textos apresentados não somente evidenciam o estágio mais recente da produção científica das ciências sociais em saúde na França, como recolocam importantes questões. De um modo geral, essas pesquisas tomam por objeto a medicina como uma prática específica de indivíduos autorizados socialmente a determinar o que é legítimo e legal quanto ao adoecimento e à cura, preocupados com a emergência de determinadas disciplinas e sua instalação institucional na hierarquia de poder (Schlumbohm, Jaisson, Monnais-Rousselot, Faure). Percebe-se uma continuidade temática e formal nesses artigos: em geral, todos centram esforços em uma contextualização histórica profunda, enfatizando as mudanças temporais e as regularidades históricas, portanto próximos de uma genealogia de cada tema.

Um segundo grupo de trabalhos refere-se aos estudos que, embora se situem nas perspectivas acima, diferem na ênfase: a saúde é aceita como objeto economicamente condicionado e através dessa abordagem é analisada. Isso significa trabalhar sociologicamente na interface da sociologia da saúde e da economia da saúde e da história, esboçando suas relações (Serre, Duval).

Somente três autores norte-americanos fogem à regra (Kleinman, Cicourel e Goffman), com seus estudos sobre a dor humana em pacientes diversos; o funcionamento concreto de um serviço médico; e as interações em salas de cirurgia de hospitais e outros espaços — todos buscando soluções microssociais para problemas essencialmente médicos ou de saúde.

A leitura desses estudos recoloca a questão do espaço que vem sendo construído pela sociologia da saúde, em especial a francesa. Retomando a dicotomia sociologia 'da medicina' versus sociologia 'na medicina', verificase que os estudos representativos da tradição francesa de sociologia médica tendem a ser sociologicamente externos ao campo médico e encaminhamse para os aspectos históricos e teóricos das disciplinas do social, a fim de analisar as práticas, os discursos sobre o adoecimento e a cura. Ao contrário, os de origem norte-americana tendem a focalizar temas internos das práticas 
ou dos serviços de saúde, perseguindo problemas concretos, cotidianos e dos microambientes das instituições médicas, com uma preocupação epistemológica e visão de mundo internas ao campo médico.

Por mais que a separação sociologia 'da' ou 'na' medicina seja um tipo ideal desatualizado, ela mantém a sua força e reaparece inesperadamente de tempos em tempos; ou, talvez, o campo da sociologia mantenha suas permanências estruturais, apesar de o movimento de maturação dessa sociologia prognosticar o desaparecimento de tal diferença.

\section{REFERÊNCIAS BIBLIOGRÁFICAS}

Chenu, Alain

2002

Micelli, Sérgio 27.1.2002

Montagner, Miguel

Ângelo

2003

Nunes, Everardo

Duarte

2003

Pinto, Louis

1996
'Une institution sans intention : la sociologie en France depuis l'après-guerre'. Actes de la Recherche en Sciences Sociales, no 141-142, pp. 46-61.

'Uma revolução simbólica'.

Folha de S. Paulo, p. 3.

'A teoria da prática de Bourdieu e a sociologia da saúde: revisitando as Actes de la Recherche em Sciences Sociales. Dissertação de mestrado, em ciências médicas, Universidade de Campinas, Campinas. (mimeo.)

'A sociologia da saúde nos Estados Unidos, Grã-Bretanha e França: panorama geral'. Ciência e Saúde Coletiva, 8(1), pp. 79-95.

'Une science des intellectuels est-elle possible?'.

Revue de Synthèse (4):345, out./dez. 